\title{
Kinetic Analysis of Plasma Insulin Disappearance in Nonketotic Diabetic Patients and in Normal Subjects
}

\author{
A TRACER STUDY WITH ${ }^{125}$ I-INSULIN
}

\author{
Renzo Navalesi, Alessandro Pilo, and Eleuterio Ferrannini, with the technical \\ assistance of PAOLO CECCHETtI and ANTONIO MASONI, C.N.R. Clinical Physiology \\ Laboratory, and the 2nd Medical Clinic, University of Pisa, 56100 Pisa, Italy
}

A B S TRACT The studies so far reported on the metabolic clearance rate of insulin in human diabetes mellitus have given conflicting results, probably because they have been conducted on few patients and have used a variety of experimental techniques and data treatments. We investigated the kinetics of insulin distribution and degradation in 35 normal subjects and in 42 nonketotic, nonobese, overtly diabetic patients, of whom 26 were above $40 \mathrm{yr}$ old and 16 were $40 \mathrm{yr}$ old or less at diagnosis. The design of the study combined $(a)$ the use of a tracer to perturb minimally the steady state and to avoid glucose infusion; $(b)$ the preparation of purified [ $\left.{ }^{125} \mathrm{I}\right]$ monoiodoinsulin, which has a metabolic behavior similar to that of native insulin; and $(c)$ noncompartmental analysis of the plasma immunoprecipitable ${ }^{125}$ I-insulin disappearance curves, which were recorded for $2 \mathrm{~h}$ after pulse i.v. injection of the tracer.

Metabolic clearance rate was found to be similar in diabetics $\left(404 \pm 18 \mathrm{ml} / \mathrm{min} \cdot \mathrm{m}^{2}\right.$, mean $\left.\pm \mathrm{SEM}\right)$ and in normals $(420 \pm 14)$, although the latter-onset patients had slightly, if not significantly, lower metabolic clearance rate values than the earlier-onset diabetics ( $385 \pm 19$ and $443 \pm 36$, respectively). The initial distribution volume of the hormone also did not significantly differ in diabetics and normals and was similar to plasma volume. The reentry rate into the initial distribution volume of the hormone and the total, plasma-equivalent distribution volume of insulin were both significantly raised in diabetics $(251 \pm 12 \mathrm{ml} / \mathrm{min}$. $\mathrm{m}^{2}$ and $10.3 \pm 0.5$ liters $/ \mathrm{m}^{2}$ ) in comparison with normals ( $195 \pm 8$ and $7.5 \pm 0.3$ ). The posthepatic delivery rate of insulin was found to be slightly raised in lateronset diabetics $\left(194 \pm 20 \mathrm{mU} / \mathrm{h} \cdot \mathrm{m}^{2}\right)$, but somewhat reduced in earlier-onset diabetics $(133 \pm 15)$ in compari-

Received for publication 9 July 1976 and in revised form 15 August 1977. son with normals $(172 \pm 14)$; these differences reflected the different basal plasma insulin concentrations in these three groups. Chronic treatment with oral hypoglycemic drugs, age, duration of the disease, and degree of metabolic control appeared to have only little effect on the kinetics of insulin.

On the basis of these results, we conclude that insulin-independent adult diabetics show, already in the fasting state, a combination of insulin resistance and insulin deficiency and a derangement in insulin distribution, the precise significance of which is uncertain.

\section{INTRODUCTION}

Although the metabolic clearance rate $(\mathrm{MCR})^{1}$ of insulin in human diabetes mellitus has been measured by several investigators, the results have been conflicting, because normal (1), slightly increased (2), and decreased $(3,4)$ MCR values have all been reported. It is clearly difficult to compare the studies so far available, because of the considerable differences in the criteria for selecting the diabetic patients, in the experimental techniques used, and in the modes in which the data were analyzed. Such discordant findings suggest that the removal of insulin from diabetic plasma does not differ greatly from normal, because otherwise, this would have been clearly detected by these studies.

A kinetic study, however, can give more information than just the degradation rate, by providing

\footnotetext{
${ }^{1}$ Abbreviations used in this paper: BIM, body mass of exchangeable insulin; DIT, diiodotyrosine; ER, exit rate; IDR, basal posthepatic insulin delivery rate; IDV, initial distribution volume of hormone; IRI, plasma concentration of endogenous insulin; MCR, metabolic clearance rate; MIT, monoiodotyrosine; RI, regulation index; $R R$, reentry rate or reversible loss; TDV, total plasma-equivalent distribution volume.
} 
estimates of the quantity of insulin in body compartments which are not accessible to direct measurement. In this way, it has been shown that, in the normal subject, glucose utilization reflects the timecourse of insulin concentration in a slowly equilibrating compartment, apparently representing the interstitial fluid of muscle and adipose tissue (5). It seemed, therefore, of interest to study the kinetics of insulin in diabetics, in whom there is a substantial impairment of insulin action on muscles and fat, possibly caused by receptor failure $(6,7)$.

We obtained complete kinetic analyses in a large series of diabetic patients and in a similar number of healthy subjects used as the control group. Nonobese, nonketotic clinical diabetics were chosen because they were thought to represent the greater part of the diabetic population. The experimental approach included the use of purified $\left[{ }^{125} \mathrm{I}\right]$ monoiodoinsulin as a tracer for native insulin and noncompartmental analysis (8) of the plasma disappearance curves.

The results showed that the MCR of insulin of these diabetic subjects was approximately normal, but the diffusion of the hormone out of the vascular compartment and its apparent distribution space were significantly, though not greatly, increased with respect to normal. Insulin resistance and relative insulin lack were also found to be associated with the fasting hyperglycemia of nonketotic diabetes mellitus.

\section{METHODS}

Patient selection. 42 diabetics who had never received insulin treatment were studied. Most of them were outpatients attending the Diabetic Unit. A thorough physical examination and a routine laboratory checkup were performed before the study, and only those patients who showed no evidence of other systemic or parenchymal diseases were included in the study. The pertinent clinical data are given in Table I; none of the patients had ketone bodies in the urine when the study was conducted. A regulation index (RI, see legend to Table I) was calculated by including all relevant data available from the patients' clinical records from $1 \mathrm{yr}$ before to $6 \mathrm{mo}$ after the study. In most study subjects, the metabolic status, evaluated in this way, was reasonably well controlled. 34 of the diabetics were on maintenance treatment with varying doses of oral hypoglycemic drugs (sulfonylureas alone or in combination with biguanides), while the remaining 8 diabetics were controlled by diet alone.

The control group consisted of 35 healthy, adult volunteers (23 females and 12 males) (Table III). ${ }^{2}$ They had nega-

\footnotetext{
${ }^{2}$ The individual data of these subjects are deposited with the National Auxiliary Publications Service (NAPS) as NAPS document No. 03171. This information may be ordered from ASIS/NAPS, Microfiche Publications, P. O. Box 3513, Grand Central Station, New York 10017. Remit in advance $\$ 3.00$ for microfiche copy, or for photocopy, $\$ 5.00$ up to 20 pages plus $25 \notin$ for additional pages. Checks should be made payable to Microfiche Publications.
}

tive family histories of diabetes mellitus, and their oral glucose tolerance test $(100 \mathrm{~g})$ was within the normal limits (9).

All diabetic patients were on a weight-maintaining diet, with an average $40 \%$ carbohydrates (at least $200 \mathrm{~g}$ of sugars/ day). The normal subjects consumed the average Italian diet, consisting of $43-48 \%$ carbohydrates, $12-17 \%$ proteins, and $35-40 \%$ fat.

Informed consent for the study was obtained from all subjects.

Experimental protocol. All studies were performed at 9 a.m., after an overnight fast, in the sitting position; all medication had been withdrawn for the preceding 12-18 $\mathrm{h}$ and thyroid uptake had been blocked by oral administration of saturated potassium iodide. A plastic cannula was inserted in an antecubital vein and kept patent by intermittent irrigation with isotonic saline. After a stabilization period of $15-20 \mathrm{~min}, 140-150 \mu \mathrm{Ci}$ of ${ }^{125} \mathrm{I}$-insulin was injected as a single bolus into a contralateral antecubital vein and blood samples were collected via the cannula at $2,2.5,3,4,5,7,9,12,15$, 20,25 , and $30 \mathrm{~min}$, and then every $10 \mathrm{~min}$ until $2 \mathrm{~h}$. Blood was drawn into tubes containing EDTA; plasma was promptly separated by centrifugation and stored at $-20^{\circ} \mathrm{C}$ until assayed.

The tracer. ${ }^{125}$ I-Insulin was prepared by the electrolytic technique (10), modified as previously described (11). In the more recent experiments, insulin was labeled by the lactoperoxidase method (12). With either technique, the iodination degree was kept between 0.04 and 0.06 mol of iodine per mole of protein, as tested by paper electrophoresis. The labeling mixture was purified by chromatography on Sephadex G-50 (Pharmacia Fine Chemicals, Inc., Piscataway, N. J.) (10) or DEAE-cellulose, according to Freychet et al. (13), or on Sephadex A-25, according to Hamlin and Arquilla (14). By all these procedures, the labeled protein was split from the unreacted iodine, as shown by paper electrophoresis. Insulin concentration in the elution fractions was measured by ultraviolet absorbance at $277.5 \mathrm{~nm}$, or by a radioimmunoassay with ${ }^{131}$ I-insulin as the labeled antigen (15). The specific activity of the tracer, estimated in these ways, was $8-10 \mathrm{mCi} / \mathrm{mg}$ when ${ }^{125}$ I-insulin was purified on Sephadex G-50, and ranged from 100 to $200 \mathrm{mCi} / \mathrm{mg}$ when ion-exchange chromatography was used. $40 \%$ of the normal subjects and $33 \%$ of the diabetic subjects received the high specific activity tracer.

Monoiodotyrosine (MIT) and diiodotyrosine (DIT) were estimated on representative samples of the protein peak according to Covelli and Wolff (16): 10- $\mu$ l aliquots were incubated with Pronase E (Merck, W. Germany) in Tris-maleic acid buffer, $\mathrm{pH} 8.2$, at $37^{\circ} \mathrm{C}$ for $2 \mathrm{~h}$. This incubation mixture was then separated by descending paper chromatography (Whatman No. 1, butanol-2 $\mathrm{N}$ acetic acid; Whatman Inc., Clifton, N. J.), and the radioactive spots were identified by reference to commercial MIT and DIT standards and subsequently counted. The DIT content was expressed as a percentage of the total radioactive amino acids. Judging from the DIT percentage in the elution samples, it was found that all the purification procedures used could efficiently separate monoiodoinsulin from diiodinated molecules.

Pooled samples from the eluate, having a DIT content of less than $2 \%$ and an immunoprecipitability of over $90 \%$, were considered to be very pure monoiodoinsulin and were therefore used for injection in the patients.

The tracer was always used within $24 \mathrm{~h}$ of preparation, although it was found to be free from significant damage as long as 1 mo later.

Analytical procedures. Immunoprecipitable radioactivity was measured in triplicate by a modification of the doubleantibody immunoprecipitation technique of Hales and Randle (17): Guinea pig anti-insulin antibodies in excess 
TABLE I

Clinical Data of the Diabetic Patients

\begin{tabular}{|c|c|c|c|c|c|c|c|c|c|}
\hline $\begin{array}{c}\text { Case } \\
\text { no. }\end{array}$ & Sex & Age & Height & Weight & $\mathbf{P I}^{*}$ & $\begin{array}{c}\text { Dura- } \\
\text { tion }\end{array}$ & Therapy & FPG $\S$ & RI \\
\hline & & $y r$ & $\mathrm{~cm}$ & kg & $\%$ & $y r$ & & $\mathrm{ng} / 100 \mathrm{ml}$ & \\
\hline 406 & $\mathbf{F}$ & 40 & 162 & 59 & 94 & 2 & $\mathbf{S}$ & 160 & 8.7 \\
\hline 412 & $\mathbf{M}$ & 31 & 170 & 64 & 90 & 2 & $\mathbf{S}$ & 167 & 5.9 \\
\hline 417 & $\mathbf{F}$ & 23 & 167 & 70 & 121 & 7 & $\mathbf{S}+\mathbf{B}$ & 152 & 5.6 \\
\hline 418 & $\mathbf{M}$ & 40 & 176 & 72 & 93 & 2 & $S+B$ & 100 & 4.2 \\
\hline 419 & $\mathbf{M}$ & 68 & 173 & 75 & 101 & 3 & S & 109 & 3.4 \\
\hline 420 & $\mathbf{M}$ & 62 & 166 & 76 & 111 & 2 & $S+B$ & 110 & 3.0 \\
\hline 424 & $\mathbf{M}$ & 60 & 178 & 88 & 125 & 0.1 & S & 150 & 5.0 \\
\hline 425 & $\mathbf{M}$ & 21 & 178 & 68 & 95 & 0.1 & $\mathbf{S}+\mathbf{B}$ & 241 & 6.0 \\
\hline 439 & $\mathbf{F}$ & 58 & 160 & 52 & 82 & 11 & $\mathbf{S}$ & 60 & 3.7 \\
\hline 440 & $\mathbf{F}$ & 49 & 168 & 68 & 102 & 6 & $\mathbf{S}+\mathbf{B}$ & 127 & 5.1 \\
\hline 441 & $\mathbf{F}$ & 63 & 165 & 55 & 82 & 3 & $\mathbf{S}$ & 238 & 3.3 \\
\hline 442 & $\mathbf{F}$ & 57 & 154 & 60 & 100 & 12 & $S+B$ & 120 & 3.4 \\
\hline 443 & $\mathbf{M}$ & 63 & 168 & 74 & 105 & 4 & $\mathbf{S}$ & 170 & 4.7 \\
\hline 470 & $\mathbf{F}$ & 26 & 153 & 39 & 76 & 0.3 & $\mathbf{S}$ & 200 & 5.2 \\
\hline 478 & $\mathbf{F}$ & 56 & 163 & 64 & 97 & 4 & S & 130 & 3.4 \\
\hline 479 & $\mathbf{M}$ & 63 & 166 & 77 & 111 & 3 & B & 110 & 3.0 \\
\hline 480 & $\mathbf{M}$ & 58 & 171 & 56 & 75 & 2 & $\mathbf{S}$ & 124 & 3.1 \\
\hline 481 & $\mathbf{M}$ & 54 & 171 & 74 & 100 & 15 & $\mathbf{S}$ & 124 & 3.0 \\
\hline 483 & $\mathbf{F}$ & 44 & 153 & 54 & 93 & 0.3 & $\mathbf{S}+\mathbf{B}$ & 131 & 5.3 \\
\hline 484 & $\mathbf{F}$ & 44 & 154 & 65 & 112 & 0.1 & Diet & 104 & 3.0 \\
\hline 485 & $\mathbf{M}$ & 32 & 172 & 79 & 109 & 5 & $\mathbf{S}$ & 130 & 3.5 \\
\hline 488 & $\mathbf{M}$ & 53 & 167 & 78 & 110 & 6 & $S+B$ & 172 & 4.0 \\
\hline 489 & $\mathbf{M}$ & 73 & 166 & 54 & 79 & 3 & $S+B$ & 285 & 7.0 \\
\hline 490 & $\mathbf{M}$ & 57 & 170 & 75 & 102 & 5 & $\mathbf{S}$ & 134 & 3.4 \\
\hline 491 & $\mathbf{M}$ & 50 & 170 & 75 & 102 & 0.1 & Diet & 173 & 4.5 \\
\hline 492 & $\mathbf{M}$ & 53 & 167 & 71 & 100 & 7 & $S+B$ & 164 & 3.5 \\
\hline 494 & $\mathbf{M}$ & 53 & 166 & 67 & 96 & 0.4 & S & 167 & 3.1 \\
\hline 497 & $\mathbf{F}$ & 35 & 155 & 53 & 95 & 0.1 & Diet & 135 & 3.0 \\
\hline 507 & $\mathbf{M}$ & 12 & 162 & 41 & 80 & 0.1 & $S+B$ & 337 & 10.0 \\
\hline 513 & $\mathbf{M}$ & 41 & 172 & 73 & 98 & 2 & S & 155 & 5.0 \\
\hline 524 & $\mathbf{M}$ & 25 & 167 & 65 & 97 & 0.1 & Diet & 89 & 3.0 \\
\hline 526 & $\mathbf{M}$ & 49 & 180 & 80 & 100 & 2 & $\mathbf{S}$ & 176 & 5.0 \\
\hline 527 & $\mathbf{M}$ & 40 & 173 & 80 & 107 & 0.2 & Diet & 135 & 3.0 \\
\hline 528 & $\mathbf{M}$ & 42 & 175 & 81 & 106 & 0.8 & $S+B$ & 139 & 4.0 \\
\hline 529 & $\mathbf{M}$ & 42 & 171 & 86 & 117 & 6 & $S+B$ & 120 & 3.0 \\
\hline 530 & $\mathbf{M}$ & 55 & 174 & 78 & 101 & 0.3 & Diet & 136 & 3.0 \\
\hline 531 & $\mathbf{M}$ & 53 & 169 & 74 & 102 & 5 & $S+B$ & 180 & 6.0 \\
\hline 533 & $\mathbf{M}$ & 57 & 173 & 72 & 95 & 0.1 & Diet & 127 & 4.0 \\
\hline 539 & $\mathbf{M}$ & 50 & 165 & 80 & 115 & 0.2 & Diet & 115 & 4.0 \\
\hline 544 & $\mathbf{M}$ & 39 & 170 & 70 & 98 & 0.2 & $S+B$ & 209 & 9.0 \\
\hline 545 & $\mathbf{F}$ & 23 & 165 & 59 & 104 & 0.1 & $S+B$ & 144 & 8.0 \\
\hline 546 & $\mathbf{F}$ & 32 & 165 & 53 & 86 & 0.4 & $\mathbf{S}$ & 224 & 8.0 \\
\hline \multicolumn{2}{|l|}{ Mean } & 46.3 & 166 & 68.0 & 99.1 & 2.9 & & 154 & 4.6 \\
\hline \multicolumn{2}{|l|}{ SEM } & 2.2 & 1.0 & 1.8 & 1.8 & 0.5 & & 8 & 0.3 \\
\hline
\end{tabular}

The regulation index (RI) was calculated by a score system as follows: $(a)$ fasting plasma glucose: points $1,2,3$, or 4 , for the ranges $<150,150-200,200-250$, and $>250 \mathrm{mg} / 100 \mathrm{ml}$, respectively; (b) 24-h glucose excretion in the urine: points $1,2,3$, or 4 , for $<10,10-20,20-40$, and $>40 \mathrm{~g}$, respectively; (c) occurrence (4 points) or not ( 1 point) of ketone bodies in the urine. The values of RI reported are averages from all clinical checks from $1 \mathrm{yr}$ before to $6 \mathrm{mo}$ after the study.

* Ponderal index (Metropolitan Life Insurance Co. tables).

† S, sulfonylureas; B, biguanides.

$\S$ Fasting plasma glucose. 
(dilution 1:500) were added to ${ }^{125}$ I-insulin-containing plasma samples, and the antigen-antibody complexes were then precipitated with rabbit anti-guinea pig gamma globulins. The precipitated complexes were collected by centrifugation at $3,000 \mathrm{~g}$ and counted in a well-type gamma counter (Nuclear Chicago Corp., Des Plaines, Ill.; efficiency 40\%). Blank values were obtained in duplicate for each sample by substituting normal guinea pig serum for the anti-insulin antibody in the incubation mixture; the radioactivity precipitated under these conditions $(2-3 \%$ on average) was considered to be nonspecific and was therefore subtracted from the specific precipitated counts. Immunoprecipitability ranged from 90 to $95 \%$ of the injected dose and of the plasma samples collected soon after injection.

Since in the late samples of the ${ }^{125} \mathrm{I}$-insulin curve the immunoprecipitable fraction was usually about 100 times less than in the early readings (Fig. 4), the nature of the nonimmunoprecipitable radioactivity was assessed by paper electrophoresis in 10 normal subjects and 10 diabetics. It was found that, both in normals and in diabetics, about $60 \%$ of the radioactivity was free iodine and about $38 \%$ had a molecular weight lower than insulin, presumably representing its degradation products.

The existence of cross-reaction between ${ }^{125} \mathrm{I}$-insulin and its degradation products was also assessed. A and B chains, obtained by sulfitolysis of tracer insulin and purified on $50 \times 2$ Dowex, and A chain fragments, produced by enzymatic hydrolysis of the A chain with $\alpha$-chymotrypsin, were added to normal serum and processed in the same run with samples containing undegraded ${ }^{125} \mathrm{I}$-insulin. Coprecipitation was found to be $0.09 \%$ and $0.47 \%$ for the $A$ and $B$ chain, respectively, and null for $A$ chain fragments.

Plasma concentration of endogenous insulin (IRI) was measured with ${ }^{131}$ I-insulin as labeled antigen (prepared by the same procedure described for ${ }^{125} \mathrm{I}$-insulin) and dextrancoated charcoal and centrifugation at $3,000 \mathrm{~g}$ for separating bound from free insulin. The inter- and intra-assay coefficients of variation were 14 and $7 \%$, respectively (18), in the range of the basal concentrations $(3-20 \mu \mathrm{U} / \mathrm{ml})$.

Plasma glucose concentration was measured by the ferricyanide technique (AutoAnalyzer, Technicon Instruments Corp., Tarrytown, N. Y.).

\section{DATA ANALYSIS}

The kinetic parameters were computed from the plasma disappearance curve $P(t)$ of immunoprecipitable ${ }^{125}$ I-insulin with a minimum assumption model (Fig. 1), which has been applied in the analysis of the kinetics of a great number of blood-borne compounds $(19,20)$. The model consists of a central compartment (accessible to sampling), usually identified with the intravascular pool, and an undetermined number of other compartments (curved arrow, Fig. 1), which

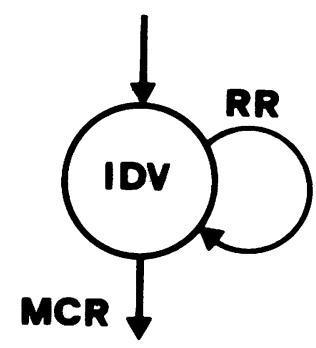

FIGURE 1 See text for explanation. represent the extravascular pool(s), reversibly exchanging with the central compartment.

The kinetic variables computed are: ${ }^{3}$

IDV (initial distribution volume, liters $\left./ \mathrm{m}^{2}\right) \quad=D / P(o)$

$\underset{\text { rate, } \mathrm{ml} / \mathrm{min} \cdot \mathrm{m}^{2} \text { ) }}{\text { MCR (metabolic clearance }}=D / \int_{0}^{\infty} P(t) \mathrm{d} t$

$k$ (initial slope, \% IDV/ min) $=[\mathrm{d} P(t) / \mathrm{d} t]_{t=0} / P(o)$

ER (exit rate from IDV, $\left.\mathrm{ml} / \mathrm{min} \cdot \mathrm{m}^{2}\right) \quad=k \cdot \mathrm{IDV}$

RR (reentry rate or reversible loss, $\left.\mathrm{ml} / \mathrm{min} \cdot \mathrm{m}^{2}\right) \quad=\mathrm{ER}-\mathrm{MCR}$

$\bar{t}_{1}$ (one-passage mean residence time in IDV, $\min ) \quad=1 / k$

$\bar{T}_{1}$ (mean total residence time in IDV, $\mathrm{min}$ ) = IDV/MCR

$\nu$ (average number of recycles through IDV)

$$
=\bar{T}_{1} / \bar{t}_{1}-1
$$

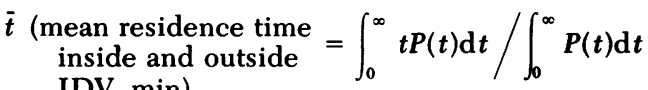
IDV, $\min$ )

TDV (total plasma-equivalent distribution volume, liters $/ \mathrm{m}^{2}$ ) $=\mathrm{MCR} \cdot \mathrm{t}$

IRI (basal plasma concentration of immunoreactive insulin, $\mu \mathrm{U} / \mathrm{ml}$ )

IDR (basal posthepatic insulin delivery rate, $\mathrm{mU} / \mathrm{h} \cdot \mathrm{m}^{2}$ )

$$
=\mathrm{MCR} \cdot \mathbf{I R I}
$$

BIM (body mass of exchangeable insulin $\mathrm{mU} / \mathrm{m}^{2}$ )

$$
=\mathrm{TDV} \cdot \mathrm{IRI}
$$

The above equations are correct given the following assumptions: $(a)$ that the sytem is linear and time-invariant for the duration of the experiment; $(b)$ that the tracer is injected at the same site as that where the tracee enters the system; and (c) that all catabolism (or irreversible loss) occurs in sites whose exchange rate with the central pool is so high that they are practically indistinguishable from it.

Assumption ( $a$ ) implies that the subject is in steady-state conditions for the duration of the experiment $(2 \mathrm{~h}$ in the studies here reported). Peripheral plasma IRI concentrations were stable, within the limits of the experimental error of the measurements, in our shortly (overnight) fasted subjects. On the other hand, when low specific activity tracer was used, nonnegligible amounts of cold insulin were administered,

${ }^{3} \mathrm{D}$ indicates the immunoprecipitable fraction of the administered dose. The values of $k, \bar{t}_{1}$, and $\bar{T}_{1}$ are not reported in this paper, because they add little to the information conveyed by other parameters. 
which introduced a perturbation into the system, as shown by the IRI values of the first 15 min after injection (Figs. 2 and 3). These increments in IRI level should not have affected the disappearance of ${ }^{125} \mathrm{I}$-insulin from the plasma to any significant extent if the insulin removal mechanisms were not saturated within the range of IRI variations induced. In this respect, we have reported (21) data showing that the disappearance curves of ${ }^{125} \mathrm{I}$-insulin under basal conditions and during glucose infusion were virtually superimposable. The same conclusion is drawn from the work of Sherwin et al. (5), who have shown that the IRI curves obtained after infusing double amounts of unlabeled hormone were essentially the same, apart from a scale factor, within the range of the physiological concentrations.

Assumption $(b)$ is not fulfilled in the kind of experiment described here, where the tracer is administered via a peripheral vein. In fact, endogenous insulin must pass through the liver before being mixed in peripheral plasma. Since it is known (22) that the liver retains considerable amounts of insulin, the peripheral injection of the tracer is actually capable of tracing only that fraction of the hormone which survives the first transhepatic passage $(23,24)$. As a consequence, the values of turnover rate reported in this study, referred to as insulin delivery rate (IDR), represent the basal posthepatic delivery rate of insulin.

Assumption $(c)$ implies that all insulin molecules eventually return to the central compartment before being degraded. However, it can also be postulated that insulin is irreversibly removed also by sites (organs and tissues) whose exchange rate with plasma is slow in comparison with the turnover rate of the hormone $(5,25)$. The consequences of assuming peripheral catabolism are the following: $(a)$ Eq. 2 will still provide a correct estimate of the overall clearance rate, but the relative amounts of the central and peripheral catabolism remain undetermined. ( $b$ ) The RR values derived from Eq. 5 will not be an estimate of the diffusion of insulin out of IDV, as it would be if all catabolism were central, but will be
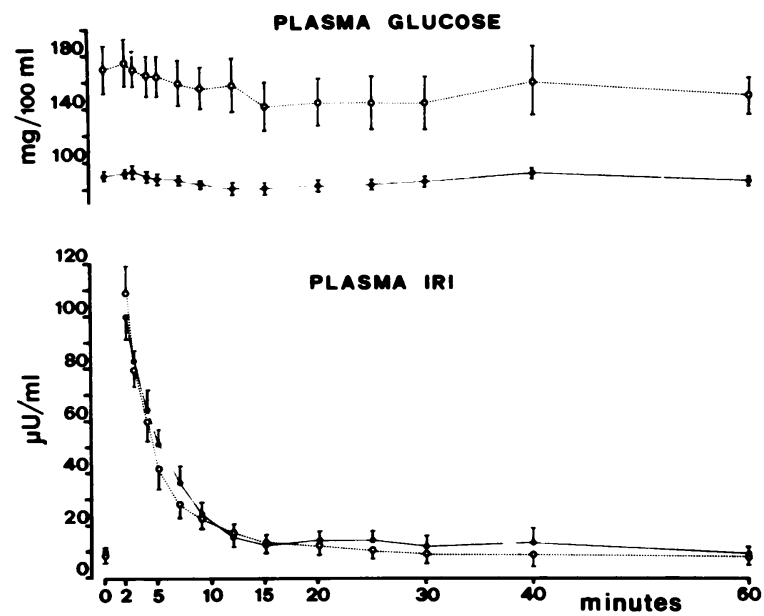

FIGURE 2 Time-course of plasma glucose and IRI concentrations after injection of $140-150 \mu \mathrm{Ci}$ of low specific activity ${ }^{125} \mathrm{I}$-insulin (corresponding to about $0.47 \mathrm{U}$ ) in 9 normal subjects $(-\bigcirc)$ and 10 diabetics $(O \cdots O)$. Means and SEM are drawn. Only the values obtained during the 0 to 60 -min interval are plotted, since those relative to the 60 to 120-min interval were not different from base-line values. In no case did the plasma glucose level fall by over $20 \%$ of the respective pre-injection value.

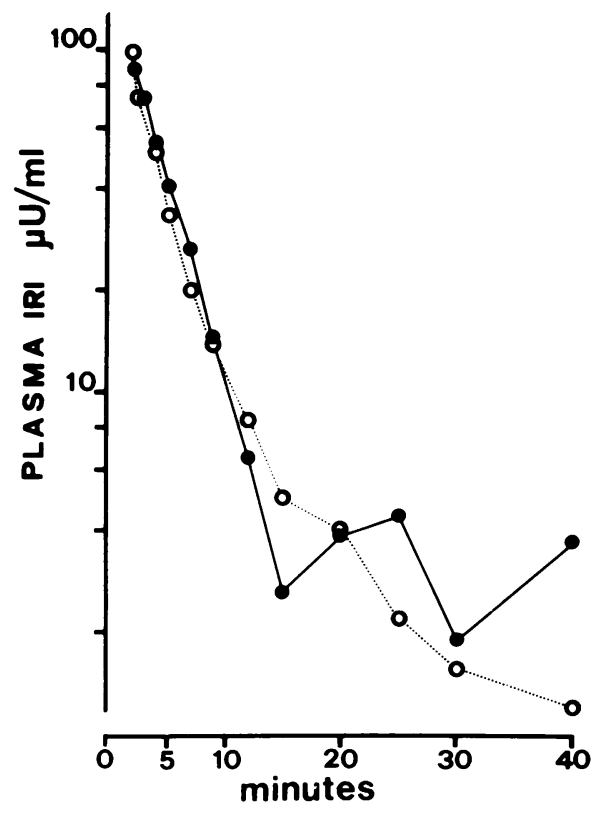

FIGURE 3 The mean values for plasma IRI concentrations in the lower panel of Fig. 2 are here plotted in semilogarithmic scale, after subtraction of the respective basal values, in normals $(-0)$ and diabetics $(O \cdots O)$. It is evident that these plasma cold insulin decay curves cannot be determined beyond $15 \mathrm{~min}$, after which time the experimental points become erratic.

actually only a reentry rate, i.e., the difference between diffusion and peripheral degradation. (c) Eq. 10 will measure only the exchangeable pool of insulin, defined as the sum of the insulin in IDV and the extravascular insulin that will eventually return to IDV before degradation (8). Thus, TDV, as derived from Eq. 10, does not include the insulin molecules leaving but not returning to IDV, because these are not exchangeable. As a result, if peripheral catabolism exists, any change in the ratio of peripheral to central removal will generate changes in the estimates of TDV simply because more (or less) molecules will come back into IDV and will therein be traceable for longer (or shorter) times. In other words, the variations in TDV will be only apparent and will not reflect any real modification of the physical distribution space of insulin.

From the computational point of view, the values of the integrals $\int_{0}^{\infty} P(t) \mathrm{d} t$ and $\int_{0}^{\infty} t P(t) \mathrm{d} t$, which enter Eqs. 2 and 9 , were analytically computed from a multi-exponential function fitted to the experimental points by a computerized peeling algorithm. Three exponential components were usually detected. However, no correspondence between the number of exponentials and the number of body insulin distribution compartments was assumed. This data treatment has been referred to as noncompartmental analysis (8). It is obvious that the values of the parameters calculated as indicated above are identical with the values generated using any pluricompartmental, parallel model (5). Alternatively, the integrals can be computed by using the trapezoidal integration of the experimental points and then adding the area of the tail of the curve, derived by monoexponential extrapolation of the last experimental points (usually from $50 \mathrm{~min}$ after injection). In our experience, both methods yielded essentially similar results. The numerical values presented in 
this paper are those computed by the trapezoidal rule. The values of the zero-time intercepts and derivatives were calculated by monoexponential interpolation of the experimental points obtained within the first 5 min after injection.

The uncertainty of the computed kinetic parameters due to the experimental error of the immunoprecipitation technique was evaluated as follows. For each experimental point of the plasma ${ }^{125} \mathrm{I}$-insulin curve, the variance of the triplicate immunoprecipitate determinations plus the variance of the duplicate blank readings was computed. These variances were then averaged by pooling all the experimental points at each sampling time. Both in normals and in diabetics, the coefficients of variation ranged from $1.8 \%$ to about $18 \%$ for the samples taken at 2 and $120 \mathrm{~min}$, respectively, and varied linearly in between. This estimate of the variance was then used in a Monte Carlo simulation: randomly generated numbers, normally distributed with zero as the mean and the variance computed as above, were added to the mean population curves and the kinetic parameters were calculated. This procedure was iterated 1,000 times, and the standard deviations and coefficients of variation were computed for each parameter (Table II). It can be seen that the uncertainty of the variables requiring the extrapolation of the time $\times$ concentration function ( $t$ and TDV) was considerably higher than that of the other parameters, and more so for the diabetic population curve, which had a slower final slope. Obviously, however, these coefficients of variation were invariably smaller than those found experimentally (Table III), because the latter included the individual variability.

Comparison of the means was performed by Student's $t$ test or, where variances were different (Fisher's $F$ ) at the 5\% level of significance, by the Behrens test (26).

\section{RESULTS}

Fig. 4 shows the mean plasma disappearance curves of the immunoprecipitable and the nonimmunoprecipitable radioactivity for both the normal and the diabetic group studied.

In Table III, the mean values for the kinetic parameters of the normal and the diabetic subjects are reported, together with the significance of the differences between the means. ${ }^{4}$

The IDV was similar in normals and diabetics ( 51 and $49 \mathrm{ml} / \mathrm{kg}$, respectively), and about $20 \%$ larger than plasma volume as measured by radioiodinated albumin $[40-50 \mathrm{ml} / \mathrm{kg}(27)]$. This difference is explained by the fact that, in the case of insulin, before mixing in plasma is complete (2-3 min), some extravascular diffusion and some degradation occur, whereby the computed zerotime concentration is lower. The ER and the MCR did not differ in the two groups, but diabetics had higher (25\%) RRs and more recycles of insulin through plasma $(\nu)$. Also, the mean residence time $(t)$ was longer in diabetics, and consequently, their TDV was expanded, by about $37 \%$ on average, over that of normals. The IRI and (IDR) did not differ, but the BIM was about $1 \frac{1}{2}$ times as great in diabetics as in nondiabetics.

${ }^{4}$ The individual values of these kinetic variables are deposited with the National Auxiliary Publications Service. See footnote 2 .
TABLE II

Uncertainty (Coefficients of Variation \%) of the Computed Parameters Due to the Experimental Error of the Immunoprecipitation Technique

\begin{tabular}{lcc}
\hline & Normals & Diabetics \\
\hline IDV & 2.0 & 1.9 \\
ER & 0.8 & 0.7 \\
MCR & 1.5 & 3.4 \\
RR & 3.1 & 5.2 \\
$\nu$ & 4.1 & 8.6 \\
$t$ & 10.8 & 28.2 \\
TDV & 9.8 & 23.2 \\
\hline
\end{tabular}

Effect of oral hypoglycemic drugs on insulin kinetics. Although acute i.v. injection of tolbutamide has been shown to produce no alteration of radioinsulin clearance (1), it is possible that chronic treatment with hypoglycemic agents might do so. Therefore, eight diabetic patients controlled by diet only were also studied. These patients (Table IV) had had diabetes for a shorter time and had significantly $(P<0.01)$ lower fasting glucose and RI values in comparison with the 34 patients on maintenance oral therapy. The kinetic results, however, were not significantly different in these two groups. Furthermore, the compari-

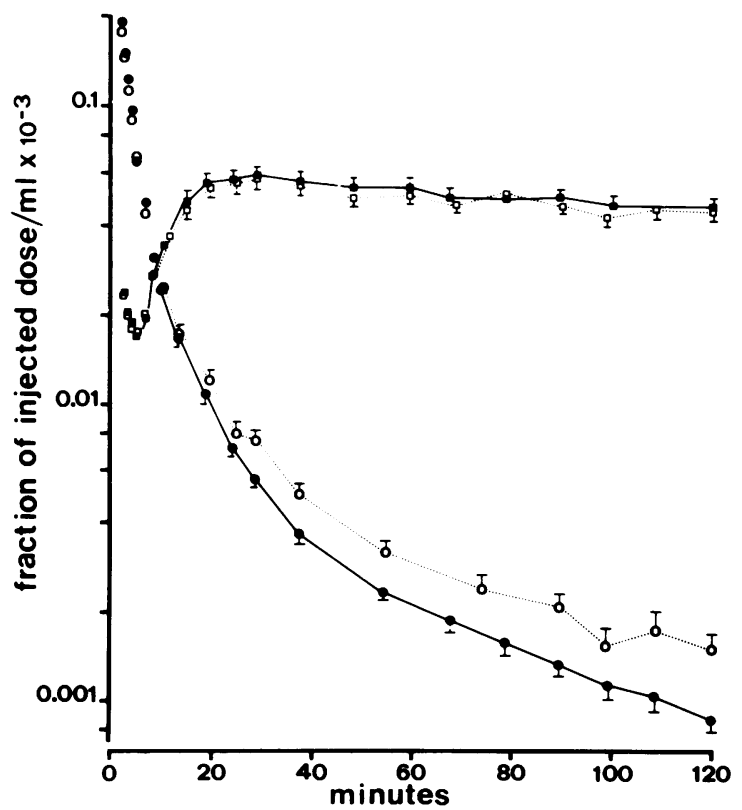

Figure 4 Plasma disappearance of immunoprecipitable ${ }^{125}$ Iinsulin and appearance of nonimmunoprecipitable radioactivity (expressed as fraction of the injected dose and plotted in semilogarithmic scale) in 35 normal subjects ($\square-\square)$ and 42 diabetic patients $(\bigcirc \cdots O$ and $\square---\square)$. Means and SEM are drawn. The immunoprecipitated counts are higher in diabetics than in nondiabetics at most of the sampling points from about $30 \mathrm{~min}$ after injection onward. 
TABLE III

Clinical and Kinetic Parameters of the Normal and the Diabetic Subjects

\begin{tabular}{|c|c|c|}
\hline & $\begin{array}{c}\text { Normals, } \\
n=35 \\
\text { (mean } \pm \text { SEM) }\end{array}$ & $\begin{array}{c}\text { Diabetics, } \\
n=42 \\
(\text { mean } \pm \text { SEM })\end{array}$ \\
\hline Age, $y r$ & $36.4 \pm 1.9$ & $46.3 \pm 2.2^{*}$ \\
\hline Ponderal index, \% & $97.3 \pm 1.8$ & $99.1 \pm 1.8$ \\
\hline Duration, $y r$ & & $2.9 \pm 0.5$ \\
\hline $\begin{array}{l}\text { FPG } \neq, m g / 100 m l \\
\text { RI }\end{array}$ & $89 \pm 3$ & $\begin{array}{l}154 \pm 8^{*} \\
4.6 \pm 0.3\end{array}$ \\
\hline IDV, liters $/ m^{2}$ & $1.9 \pm 0.1$ & $1.9 \pm 0.1$ \\
\hline $\mathrm{ER}, \mathrm{ml} / \mathrm{min} \cdot \mathrm{m}^{2}$ & $614 \pm 20$ & $655 \pm 23$ \\
\hline $\mathrm{MCR}, \mathrm{ml} / \mathrm{min} \cdot \mathrm{m}^{2}$ & $420 \pm 14$ & $404 \pm 18$ \\
\hline $\mathrm{RR}, \mathrm{ml} / \mathrm{min} \cdot \mathrm{m}^{2}$ & $195 \pm 8$ & $251 \pm 12^{*}$ \\
\hline$\nu$ & $0.47 \pm 0.02$ & $0.67 \pm 0.04^{*}$ \\
\hline$t, \min$ & $18.2 \pm 0.7$ & $26.9 \pm 1.5^{*}$ \\
\hline TDV, liters $/ m^{2}$ & $7.5 \pm 0.3$ & $10.3 \pm 0.5^{*}$ \\
\hline IRI, $\mu U / m l$ & $7.0 \pm 0.6$ & $7.6 \pm 0.7$ \\
\hline IDR, $m U / h \cdot m^{2}$ & $172 \pm 14$ & $173 \pm 15$ \\
\hline $\mathrm{BIM}, m U / m^{2}$ & $51 \pm 4$ & $75 \pm 7^{*}$ \\
\hline
\end{tabular}

The reported levels of significance refer to the comparison with the group of 35 normal subjects.

$* P<0.01$.

$\$$ Fasting plasma glucose.

son of these two treated and untreated groups of diabetics with the control group showed the same differences in the kinetic variables as those found between the group of all diabetics and normals (Table III), although with the untreated patients, statistical significance was attained only for $t$ and TDV, probably owing to the small number of data. Thus, the long-term administration of hypoglycemic agents did not significantly affect ${ }^{125} \mathrm{I}$-insulin degradation in our patients, in agreement with the results of animal studies (28). This is not surprising, since some in vitro inhibition of insulin-degrading enzymes has been shown only with tolbutamide (29), but at concentrations much higher than the plasma levels presumably achieved in our patients $12-18 \mathrm{~h}$ after their last therapeutic dose (30).

Effect of the age of onset of diabetes on insulin kinetics. In the present series, 26 diabetics were older and 16 younger than $40 \mathrm{yr}$ of age when the diagnosis was made. The clinical features and the follow-up of these patients' disease confirmed that in the subgroup of later-onset subjects there were only classical maturity-onset diabetics. The younger subgroup, however, contained seven patients with maturity-onset-type diabetes in youth and nine patients who, although free from ketosis at the moment of the kinetic study, required insulin a few weeks afterwards.

The direct comparison (Table V) of these two sub- groups showed that the younger patients had had the disease for a shorter time $(P<0.05)$, were in worse metabolic control (RI) $(P<0.05)$, and had lower fasting plasma insulin levels $(P<0.01)$ and delivery rates $(P<0.05)$ than the older group. However, when each of these two subgroups was compared with the control group, the same differences were found in the kinetic parameters as those existing between the group of all diabetics and normals, with the exception of BIM, which was not significantly larger in the earlier-onset patients than in the controls.

Thus, the age of onset of diabetes was only clearly reflected in those parameters (IDR and BIM) that depend on insulin concentration, although IDV, ER, RR, and MCR revealed a trend toward being higher in the younger than in the maturity-onset diabetic subjects.

In comparing the 26 later-onset patients (mean age $54.5 \mathrm{yr}$ ) with the control group (mean age $36.4 \mathrm{yr}$ ), mismatching for age was a concern. The nondiabetic subjects were therefore subdivided into two subgroups according to their age. No differences, however, could be found in any of the kinetic variables between the 24 subjects under 40 and the 11 over $40 \mathrm{yr}$ of age, or between each of these subgroups and any of the groups of diabetics. In addition, in the normals, none of the kinetic parameters was correlated with age.

Effect of age, weight, duration of diabetes, metabolic

TABLE IV

Clinical and Kinetic Parameters of the Diabetic Subjects, Subdivided into Treated (Oral Hypoglycemic Drugs) and Untreated (Diet) Patients

\begin{tabular}{|c|c|c|}
\hline & $\begin{array}{c}\text { Treated, } \\
n=34 \\
(\text { mean } \pm \text { SEM) }\end{array}$ & $\begin{array}{c}\text { Untreated, } \\
n=8 \\
\text { (mean } \pm \text { SEM) }\end{array}$ \\
\hline Age, $y r$ & $46.8 \pm 2.6^{*}$ & $44.5 \pm 3.8$ \\
\hline Ponderal index, \% & $98.2 \pm 2.1$ & $103.0 \pm 2.7$ \\
\hline Duration, yr & $3.6 \pm 0.6$ & $0.2 \pm 0.03$ \\
\hline FPG $\S, m g / 100 m l$ & $161 \pm 9^{*}$ & $125 \pm 9^{*}$ \\
\hline $\mathbf{R I}$ & $4.9 \pm 0.3$ & $3.4 \pm 0.2$ \\
\hline IDV, liters $/ m^{2}$ & $1.9 \pm 0.1$ & $1.9 \pm 0.1$ \\
\hline $\mathrm{ER}, \mathrm{ml} / \mathrm{min} \cdot \mathrm{m}^{2}$ & $650 \pm 25$ & $677 \pm 59$ \\
\hline $\mathrm{MCR}, \mathrm{ml} / \mathrm{min} \cdot \mathrm{m}^{2}$ & $394 \pm 21$ & $446 \pm 28$ \\
\hline $\mathrm{RR}, \mathrm{ml} / \mathrm{min} \cdot \mathrm{m}^{2}$ & $255 \pm 12^{*}$ & $232 \pm 34$ \\
\hline$\nu$ & $0.71 \pm 0.05^{*}$ & $0.51 \pm 0.06$ \\
\hline$t, \min$ & $27.3 \pm 1.8^{*}$ & $25.2 \pm 2.6 \sharp$ \\
\hline TDV, liters $/ m^{2}$ & $10.1 \pm 0.5^{*}$ & $11.4 \pm 1.5 \ddagger$ \\
\hline IRI, $\mu U / m l$ & $7.7 \pm 0.8$ & $7.2 \pm 1.5$ \\
\hline IDR, $m U / h \cdot m^{2}$ & $172 \pm 17$ & $180 \pm 32$ \\
\hline $\mathrm{BIM}, m U / m^{2}$ & $76 \pm 9 *$ & $69 \pm 10$ \\
\hline
\end{tabular}

The reported levels of significance refer to the comparison with the group of 35 normal subjects.

${ }^{*} P<0.01$.

$\ddagger P<0.05$.

$\S$ Fasting plasma glucose. 
TABLE V

Clinical and Kinetic Parameters of the Diabetic Subjects, Subdivided According to the Age of Onset of Diabetes

\begin{tabular}{|c|c|c|}
\hline & $\begin{array}{c}\text { Diabetics, } \\
>40 \mathrm{yr}, n=26 \\
(\mathrm{mean} \pm \mathrm{SEM})\end{array}$ & $\begin{array}{c}\text { Diabetics, } \\
\leqslant 40 \mathrm{yr}, n=16 \\
(\text { mean } \pm \text { SEM })\end{array}$ \\
\hline Age, $y r$ & $54.5 \pm 1.5^{*}$ & $29.9 \pm 2.3$ \\
\hline Ponderal index, \% & $101.0 \pm 2.1$ & $96.1 \pm 3.1$ \\
\hline Duration, $y r$ & $3.7 \pm 0.7$ & $1.4 \pm 0.6$ \\
\hline FPG $\S, m g / 100 m l$ & $145 \pm 8^{*}$ & $172 \pm 18^{*}$ \\
\hline RI & $4.0 \pm 0.2$ & $5.9 \pm 0.7$ \\
\hline IDV, liters $/ m^{2}$ & $1.9 \pm 0.1$ & $2.0 \pm 0.1$ \\
\hline $\mathrm{ER}, \mathrm{ml} / \mathrm{min} \cdot \mathrm{m}^{2}$ & $625 \pm 24$ & $714 \pm 46$ \\
\hline $\mathrm{MCR}, \mathrm{ml} / \mathrm{min} \cdot \mathrm{m}^{2}$ & $385 \pm 19$ & $443 \pm 36$ \\
\hline $\mathrm{RR}, \mathrm{ml} / \mathrm{min} \cdot \mathrm{m}^{2}$ & $241 \pm 11^{*}$ & $270 \pm 27 \ddagger$ \\
\hline$\nu$ & $0.67 \pm 0.05^{*}$ & $0.66 \pm 0.09$ \\
\hline$t, \min$ & $27.7 \pm 1.9^{*}$ & $25.5 \pm 2.6 \ddagger$ \\
\hline TDV, liters $/ m^{2}$ & $10.1 \pm 0.6^{*}$ & $10.8 \pm 1.0^{*}$ \\
\hline IRI, $\mu U / m l$ & $8.7 \pm 0.9$ & $5.5 \pm 0.7$ \\
\hline IDR, $m U / h \cdot m^{2}$ & $194 \pm 20$ & $133 \pm 15$ \\
\hline $\mathrm{BIM}, m U / m^{2}$ & $83 \pm 9 *$ & $60 \pm 11$ \\
\hline
\end{tabular}

The reported levels of significance refer to the comparison with the group of 35 normal subjects.

$* P<0.01$.

$\ddagger P<0.05$.

$\S$ Fasting plasma glucose.

control, and plasma insulin level on insulin kinetics. The age of diabetics bore a direct relationship with IRI $(r=0.34, P<0.05)$, and an inverse relationship with ER $(r=0.34, P<0.05)$ and with MCR $(r=0.35$, $P<0.05$ ). The patients' relative weight (Ponderal index) was directly related to IDR $(r=0.30, P<0.05)$. A longer duration of the disease was associated with lower ER $(r=0.35, P<0.05)$ and MCR $(r=0.46, P$ $<0.01)$ values, and with an increased number of recycles of the hormone through plasma $(r=0.35, P$ $<0.05$ ). A worse regulation of the hyperglycemia, on the other hand, was found in the patients with lower IRI concentrations $(r=0.39, P<0.05)$ but higher ER $(r=0.32, P<0.05)$ and MCR $(r=0.37, P<0.05)$ readings.

Lower levels of circulating insulin were found to be significantly associated with higher ER $(r=0.50, P$ $<0.001)$, MCR $(r=0.39, P<0.05)$, and RR $(r=0.38$, $P<0.05)$ of the hormone.

The overall picture which these relationships suggest is that mature, longer-term, well-controlled diabetics have more circulating insulin but slower flow rates (ER, MCR, and RR) than their younger, recently diagnosed counterparts with less satisfactory metabolic balance. These findings are similar to those emerging from the comparison of the two subgroups of diabetics in Table $\mathrm{V}$.

Interrelationship of the kinetic variables. MCR was highly significantly $(P<0.001)$ related to $R R$ in a direct fashion in the control subjects, but not in diabetics (Fig. 5). In fact, the mean number of recycles of insulin in its IDV $(\nu=R R / M C R)$ was relatively constant in the normal subjects (coefficient of variation 23\%), but was more scattered in diabetics (coefficient of variation $42 \%$ ), suggesting that the two groups under study were, with regard to this variable, separated.

A strong $(P<0.001)$ positive correlation was found to exist between RR and TDV, both in normals and in diabetics (Fig. 6).

\section{DISCUSSION}

The validity of iodoinsulin as a tracer for native insulin has been repeatedly questioned $(31,32)$. Lower values for MCR have been reported by those investigators $(1,33,34)$ who used tracer radioinsulin in comparison with the findings of those $(1,5,35)$ who employed cold insulin (Table VI). On the contrary, in the present study, we report that the MCR of ${ }^{125}$ I-insulin in 35 healthy subjects was found to be $727 \mathrm{ml} / \mathrm{min} \cdot 1.73 \mathrm{~m}^{2}$, a figure that compares well with the $780 \mathrm{ml} / \mathrm{min} \cdot 1.73$ $\mathrm{m}^{2}$ reported by Sherwin et al. (5), and the $860 \mathrm{ml} / \mathrm{min}$

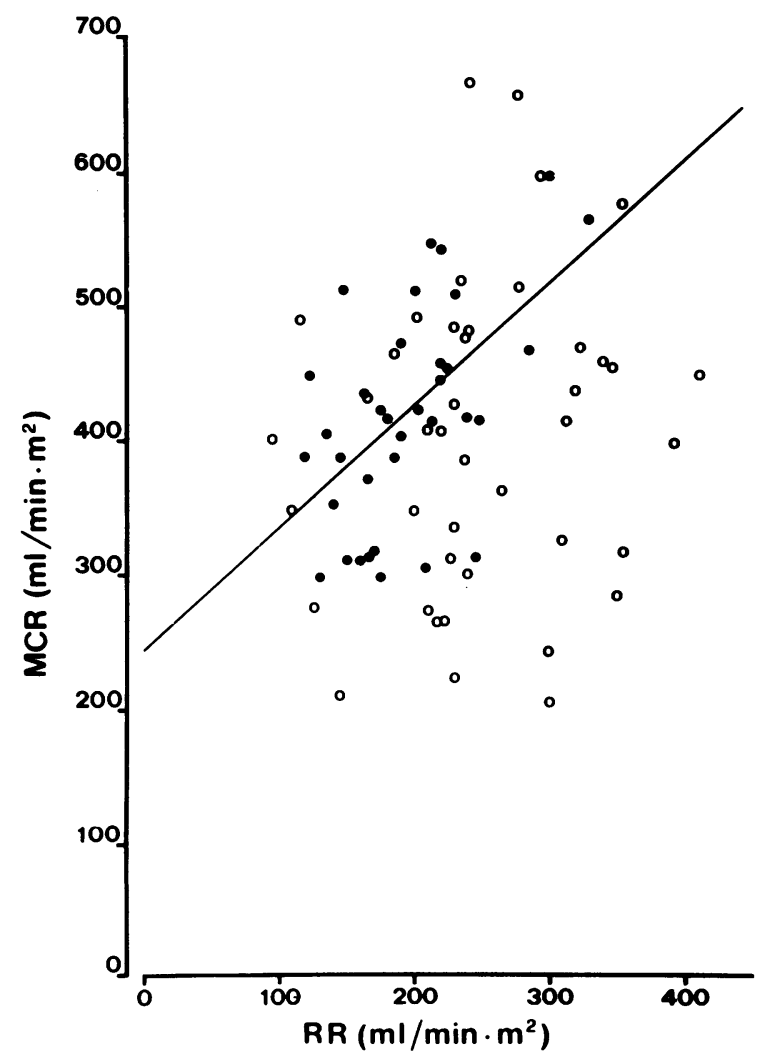

FIGURE 5 Plot of the metabolic clearance rate (MCR) of insulin vs. its rate of reentry into the initial distribution volume (RR) in normals (solid circles) and in diabetics (open circles). The correlation is significant $(P<0.001)$ only for normals $(y=246+0.90 x, r=0.54)$. 


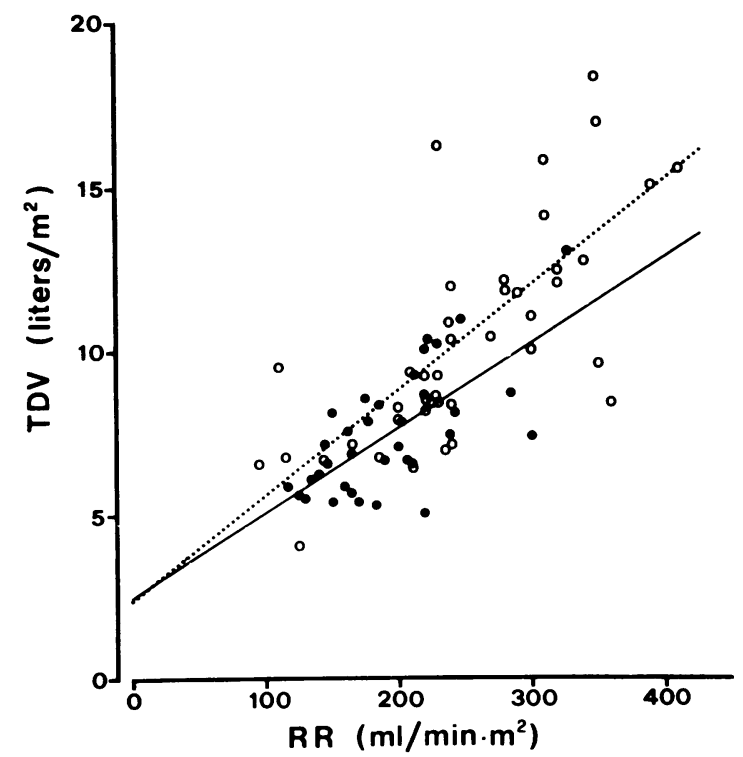

FIGURE 6 Correlation between the total distribution volume (TDV) of insulin and its rate of reentry into the initial distribution volume (RR), in normals $(-0)$ and in diabetics $(\mathrm{O} \cdots \mathrm{O})$. The respective equations of the regression lines are: $y=2.48+0.03 x, r=0.69 ;$ and $y=2.42+0.03 x, r=0.73$.

obtained by Genuth (1), with unlabeled hormone. The inconsistency between our results with tracer insulin and those previously published could be explained by differences in the quality of the radioinsulin employed. Indeed, in our preparations, the iodination degree was kept as low as 0.05 iodine atoms per molecule on average, and the labeling mixture was always purified to take out overiodinated species. It is established, in fact, that the rate and extent of degradation of iodoinsulins are inversely related to the iodination degree $(36$,
37). Lightly iodinated insulin, on the other hand, retains full immunological reactivity $(32,38)$, biological activity $(32,14)$, and binding to membrane receptors (13) and is efficiently degraded by fat (39) and liver $(37,40)$ cells.

Direct evidence bearing on this point is provided by the experiments reported in Table VII: When two subjects were first given lightly iodinated radioinsulin and then a mixture containing over $30 \%$ DIT, MCR fell by roughly $30 \%$. In addition, if one compares the plasma disappearance of cold insulin, recorded in 10 study subjects who received low specific activity tracer (Fig. 3), with the decay of ${ }^{125}$ I-insulin (Fig. 4), it can be seen that both decline with a half-time of about $3 \mathrm{~min}$; furthermore, the MCR computed by monoexponential interpolation of the experimental points of the first $15 \mathrm{~min}$ is $460 \mathrm{ml} / \mathrm{min} \cdot \mathrm{m}^{2}$ for cold insulin, and $\mathbf{4 4 0}$ for radioactive insulin. Thus, at least during this initial period, the labeled and the unlabeled molecules were being handled indistinguishably by the same subject.

Although there are sufficient grounds to conclude that $\left[{ }^{125} \mathrm{I}\right]$ monoiodoinsulin and exogenous unlabeled insulin have substantially the same behavior, the validity of applying the results of the present kinetic analysis to the endogenous, biologically active hormone could still be questioned. In particular, it could be supposed that the long "tails" of the plasma decay curves, emerging about $30 \mathrm{~min}$ after injection when the radioactivity is less than $3 \%$ of its initial value, are due to a labeled, partially degraded derivative of the tracer, which, though still immunoreactive, is cleared from plasma at a slower rate than insulin itself. In this case, the larger tail areas of diabetics, which generated prolonged residence times in the computation, could simply reflect the accumulation of this derivative, consequent to its

TABLE VI

Values for the Metabolic Clearance of Insulin in the Normal Subject (Reported from Various Authors)

\begin{tabular}{|c|c|c|c|c|c|c|}
\hline Author and year & $\begin{array}{c}\text { No. of } \\
\text { subjects }\end{array}$ & Insulin & Dose & Method & MCR & TDV \\
\hline & & & $U$ & & $\begin{array}{l}\mathrm{ml} / \mathrm{min} \\
1.73 \mathrm{~m}^{2}\end{array}$ & $\begin{array}{l}\text { liters/ } \\
1.73 \mathrm{~m}^{2}\end{array}$ \\
\hline Stern et al., $1968(52)$ & 10 & ${ }^{131}$ I-Insulin (bovine) & 0.34 & Single injection & $180^{*}$ & - \\
\hline Silvers et al., 1969 (33) & 6 & ${ }^{131}$ I-Insulin (bovine) & 0.34 & Single injection & $136^{*}$ & 9.9 \\
\hline Franckson et al., 1971 (34) & 8 & ${ }^{125}$ I-Insulin (porcine) & 5 & 80-min infusion & $546^{*}$ & - \\
\hline \multirow[t]{2}{*}{ Genuth, 1972 (1) } & 8 & ${ }^{131}$ I-Insulin (bovine) & 0.6 & 180-min infusion & 227 & - \\
\hline & 8 & Pork insulin & $?$ & 180-min infusion & 861 & - \\
\hline Sönksen et al., 1973 (35) & 10 & Human insulin & 0.9 & 30-min infusion & $2,380 * t$ & 5.8 \\
\hline Sherwin et al., 1974 (5) & 16 & Pork insulin & $\begin{array}{l}1.8 \\
6.3 \text { or } \\
12.6\end{array}$ & $\begin{array}{l}\text { Single injection } \\
80 \text {-min infusion }\end{array}$ & 780 & 10.9 \\
\hline Navalesi et al., 1975 (21) & 10 & ${ }^{125}$ I-Insulin (porcine) & 0.2 & Single injection & 747 & 12.2 \\
\hline
\end{tabular}

* Value normalized for $70 \mathrm{~kg}$ of body weight, because data for body surface were not available.

† This value refers to basal insulin concentrations. The same authors give a value of $684 \mathrm{ml} / \mathrm{min} \cdot 1.73 \mathrm{~m}$ at $\mathrm{plasma}$ insulin levels of $89 \mu \mathrm{U} / \mathrm{ml}$. 
TABLE VII

Effect of Heavy Iodination on the Metabolic Disposition of Insulin

\begin{tabular}{lcccc}
\hline & \multicolumn{4}{c}{ Case number } \\
\cline { 2 - 5 } & 503 & 503 bis & 516 & 516 bis \\
\hline IDV, liters $/ \mathrm{m}^{2}$ & 2.3 & 2.0 & 2.2 & 2.3 \\
$\mathrm{ER}, \mathrm{ml} / \mathrm{min} \cdot \mathrm{m}^{2}$ & 763 & 695 & 661 & 697 \\
$\mathrm{MCR}, \mathrm{ml} / \mathrm{min} \cdot \mathrm{m}^{2}$ & 551 & 431 & 514 & 314 \\
$\mathrm{RR}, \mathrm{ml} / \mathrm{min} \cdot \mathrm{m}^{2}$ & 212 & 264 & 148 & 383 \\
$\nu$ & 0.38 & 0.61 & 0.29 & 1.22 \\
$\boldsymbol{t}, \min$ & 16.8 & 30.2 & 12.8 & 66.7 \\
TDV, liters $/ \mathrm{m}^{2}$ & 9.3 & 13.0 & 6.6 & 20.9 \\
\hline
\end{tabular}

The cases identified as "bis" are the studies where heavily iodinated insulin was injected.

slower clearance in these patients in comparison with the normal subject. Such a derivative, however, should not be the free A or B chain, since neither is immunoreactive (and labeled A or B chains did not appreciably coprecipitate in our immune assay system). In addition, it can be presumed that the putative derivative would be produced not only from iodinated insulin but also from cold insulin, because the ${ }^{125} \mathrm{I}$ insulin curves of our normal subjects and those computed by Sherwin and co-workers (5) for exogenous unlabeled insulin with a $2-\mathrm{h}$, single-injection experiment have comparable residence times $(18.2 \pm 4.1 \mathrm{SD}$ $\min$ vs $14.0 \pm 3.1$ ). The conclusion would then be that diabetics have raised plasma concentrations of some immunoreactive endogenous material which is other than monomeric insulin but is somehow derived from it. This hypothesis raises once again the controversies on the state of the hormone in blood (41) and the existence of "abnormal" insulins in diabetes (42), which years of experimentation have failed to settle (43). We shall therefore keep this hypothesis as a general reservation, applicable to the whole body of knowledge created by means of the immune assay, and shall base the discussion of our results on the assumption that we were measuring only monoiodoinsulin throughout the disappearance curve.

Our diabetics had MCR values similar to those of normals, regardless of their fasting plasma glucose level or the quality of their metabolic regulation. This suggests, on the one hand, that the degradation rate is not a major means for controlling the effect of insulin on glucose utilization. On the other hand, the converse is also true: changing glucose levels are without effect on insulin removal.

Both these conclusions are in keeping with the findings of Reaven and his co-workers (44), who measured similar equilibrium concentrations after infusing the same amount of insulin in normal subjects and in patients with variable degrees of glucose intolerance and insulin resistance. From our studies, there is not more than an indication that longer-term diabetics have slightly reduced MCR (as well as ER and RR) as a result of either aging or the duration of diabetes (or both), whereas earlier-onset patients may have somewhat higher insulin flow parameters than normal. Incidentally, differences in age could account, at least in part, for the discordant results reported for insulin MCR in diabetics.

RR reflects the extravascular diffusion on insulin on the condition that IDV represents the intravascular space and that all catabolism is central (see Data Analysis). RR will then be related to plasma volume, to the permeability of the capillary membranes, and to the pressure gradients across them. According to this line of reasoning, the correlation between RR and MCR (Fig. 5) can be interpreted as evidence that the rate of insulin degradation is also dependent on the amount of it that is made available to the degradative sites through diffusion. This relationship was lost in diabetics, who, on average, had significantly higher RR than normal. This could be explained by an increased capillary permeability in our diabetics. With regard to this possibility, there is evidence to show that diabetes is associated with increased permeability and increased hydrostatic pressure in the microcirculation, resulting in an abnormal extravasation of plasma proteins (45). Increased transcapillary escape rates of albumin and globulins have been found both in long-term diabetics (45) and, more recently, in short-term juvenile diabetics in poor metabolic control (46), and have been connected with diabetic microangiopathy. In particular, in our group of younger, less well-controlled diabetics (Table V), RR was raised even more than in older diabetics, suggesting that hyperglycemia itself or hypoinsulinemia (or both) may play a role (47).

It should also be noted that, if peripheral catabolism is assumed to exist, the rise in RR could also be accounted for by the concomitant reduction in MCR (as was the case for our later-onset patients [Table V]), which would thus contribute to increase the rate of return of insulin to plasma through lymph (48).

The TDV of insulin was found to be about $20 \%$ of the body weight of our normal subjects. This value agrees well with the about $16 \%$ of body weight, obtained by Sherwin et al. (5) in 16 healthy volunteers, with the use of unlabeled insulin and a model reducible to ours (see Data Analysis). This volume has been identified with inulin space, a measure of the extracellular space. Although this identification seems possible, it should be observed that: $(a)$ the reported estimates of inulin space vary from 16 to $24 \%$ of body weight, according to the experimental technique and data analysis employed (27); (b) the TDV of insulin is plasma-equivalent, and therefore, it reflects not only the physical distribution space but also possible concentration gradients between the intra- and the extra- 
vascular pool; and $(c)$ the estimates of TDV, obtained with our model, are the minimal possible; in fact, if some degradation is assumed to occur in slowly exchanging degradative sites, the distribution volume of the molecules leaving but not returning to plasma should be added.

According to these considerations, the expanded TDV of the diabetic patients, which has been found also by Frost et al. (3), admits several explanations: (a) The physical distribution space, i.e., the extracellular fluid, is enlarged; $(b)$ the increase in the exchangeable TDV is only apparent, resulting from reduced degradation rate at sites which slowly equilibrate with plasma; and $(c)$ the ratio of the mean extravascular to the intravascular concentration of insulin is increased. With reference to the first explanation, there is some evidence (49) that blood volume and, possibly, the extracellular fluid are elevated in uncontrolled but nondehydrated diabetics, as an osmotic effect of hyperglycemia. This effect alone, however, is not enough to account for the over 5 liters of excess TDV of our patients (50). In addition, their plasma glucose levels were only moderately raised, and ketone bodies were absent.

Considering the second explanation, it has been shown that insulin is cleared also in slowly equilibrating tissues, such as skin, muscle, and fat $(5,25)$, and that its clearance by the forearm is reduced in diabetics (25). However, as we measured essentially normal overall clearance rates in diabetics, no inference concerning the relative entities of peripheral vs. central degradation rates can be made.

Lastly, with regard to the third hypothesis, since the extravascular concentration of a protein is also dependent on its rate of egress from plasma (51), a raised TDV could simply mean that more insulin is accumulated in the extravascular space of diabetics as a result of increased RR. This would explain the observed correlation between RR and TDV (Fig. 6).

It must be said that all these interpretations are compatible with the kinetic results presented here, but their likelihood, magnitude, and pathophysiological relevance should be examined by other experimental approaches.

Maturity-onset patients delivered about $8 \mathrm{U}$ of insulin per day into the systemic circulation under basal conditions, in accordance with previous estimates $(1,5,52,53)$. This delivery was slightly higher than normal and, in the presence of raised plasma sugar, means that insulin-independent diabetics have tissue resistance to the action of insulin already in the postabsorptive state and produce less insulin in response to the hyperglycemic stimulus than normals would do. The IDR figure for the younger patients (5.5 U/day), on the other hand, shows that they were suffering from some insulin lack.

In conclusion, although insulin degradation is es- sentially unchanged in nonketotic diabetes mellitus with respect to normal, a combination of relative insulin deficiency, insulin resistance, and a subtle derangement in insulin distribution can be demonstrated in many diabetic patients. The causative mechanism(s) of the latter abnormality are ill defined at present. One possible consequence of this maldistribution is that the ratio of insulin concentration at the sites of action to that in plasma is higher than normal. In this case, it would seem logical to link such "extravascular hyperinsulinism" with the receptor impairment of diabetes mellitus.

\section{REFERENCES}

1. Genuth, S. M. 1972. Metabolic clearance of insulin in man. Diabetes. 21: 1003-1012.

2. Orskov, H., and N. J. Christensen. 1969. Plasma disappearance rate of injected human insulin in juvenile diabetic, maturity-onset diabetic, and nondiabetic subjects. Diabetes. 18: 653-659.

3. Frost, D. P., M. C. Srivastava, R. H. Jones, J. D. N. Nabarro, and P. H. Sönksen. 1973. The kinetics of insulin metabolism in diabetes mellitus. Postgrad. Med.J. 49: 949-954.

4. Stimmler, L., K. Mashiter, G. I. A. I. Snodgrass, B. Boucher, and M. Abrams. 1972. Insulin disappearance after intravenous injection and its effect on blood glucose in diabetic and non-diabetic children and adults. Clin Sci. (Oxf.). 42: 337-344.

5. Sherwin, R. S., U. J. Kramer, J. D. Tobin, P. A. Insel, J. E. Lilienquist, M. Berman, and R. Andres. 1974. A model of the kinetics of insulin in man. J. Clin. Invest. 53: $1481-1492$.

6. Olefsky, J. M., and G. M. Reaven. 1974. Decreased insulin binding to lymphocytes from diabetic patients. J. Clin. Invest. 54: 1323-1328.

7. Olefsky, J. M., and G. M. Reaven. 1976. Insulin binding to monocytes and total mononuclear cells from normal and diabetic patients. J. Clin. Endocrinol. Metab. 43: 232-234.

8. Oppenheimer, J. H., H. L. Schwartz, and M. I. Surks. 1975. Determination of common parameters of iodothyronine metabolism and distribution in man by noncompartmental analysis. J. Clin. Endocrinol. Metab. 41: 319-324.

9. Fajans, D. S., and J. S. Conn. 1959. The early recognition of diabetes mellitus. Ann. N. Y. Acad. Sci. 82: 208-218.

10. Rosa, U., G. A. Scassellati, F. Pennisi, N. Riccioni, P. Giagnoni, and R. Giordani. 1964. Labelling of human fibrinogen with $\mathrm{I}^{131}$ by electrolytic iodination. Biochim. Biophys. Acta. 86: 519-526.

11. Navalesi, R., A. Pilo, and E. Ferrannini. 1976. Insulin kinetics after portal and peripheral injection of ${ }^{125} \mathrm{I}$ insulin. II. Experiments in the intact dog. Am. J. Physiol. 230: 1630-1636.

12. Sodoyez, J. C., F. Sodoyez-Goffaux, N. M. Goff, A. E. Zimmerman, and E. R. Arquilla. 1975. ${ }^{127} \mathrm{I}-$ or carrierfree ${ }^{125}$ I-monoiodoinsulin. Preparation, physical, immunological, and biological properties, and susceptibility to "insulinase" degradation. J. Biol. Chem. 250: 42684277.

13. Freychet, P., J. Roth, and D. M. Neville, Jr. 1971. Monoiodoinsulin: demonstration of its biological activity and binding to fat cells and liver membranes. Biochim. Biophys. Res. Commun. 43: 400-408. 
14. Hamlin, J. L., and E. R. Arquilla. 1974. Preparation, purification and characterization of a biologically active derivative substituted predominantly on tyrosine Al4. J. Biol. Chem. 249: 21-32.

15. Citti, L., E. Ferrannini, L. Battini, and R. Navalesi. 1976. Radioimmunoassay of labeled and unlabeled insulin mixtures. J. Nucl. Biol. Med. 20: 75-78.

16. Covelli, I., and J. Wolff. 1966. Iodination of the normal and buried tyrosyl residues of lysozyme. I. Chromatographic analysis. Biochemistry. 5: 860-866.

17. Hales, C. N., and P. J. Randle. 1963. Immunoassay of insulin with insulin-antibody precipitate. Biochem. J. 88: $137-146$.

18. Pilo, A., and G. C. Zucchelli. 1975. Automatic treatment of radioimmunoassay data: an experimental validation of the results. Clin. Chim. Acta. 64: 1-9.

19. Rescigno, A., and E. Gurpide. 1973. Estimation of average times of residence, recycle, and interconversion of bloodborne compounds using tracer methods. J. Clin. Endocrinol. Metab. 36: 263-276.

20. Gurpide, E. 1975. Tracer Methods in Hormone Research. Springer Verlag, Berlin. 105-128.

21. Navalesi, R., A. Pilo, S. Lenzi, and L. Donato. 1975. Insulin metabolism in chronic uremia and in the anephric state: effect of the dialytic treatment. J. Clin. Endocrinol. Metab. 40: 70-80.

22. Field, J. B. 1972. Insulin extraction by the liver. Handb. Physiol. 1(Sect. 7 Endocrinology): 505.

23. Madison, L. L., and N. M. Kaplan. 1958. The hepatic binding of $\mathrm{I}^{131}$-labeled insulin in human subjects during a single transhepatic circulation. J. Lab. Clin. Med. 52: 927-933.

24. Pilo, A., Navalesi, R., and E. Ferrannini. 1976. Insulin kinetics after portal and peripheral injection of ${ }^{125} \mathrm{I}$ insulin. I. Data analysis and modeling. Am. J. Physiol. 230: 1626-1630.

25. Butterfield, W. J. H., C. J. Garratt, and M. J. Whichelow. 1963. Peripheral hormone action: studies on the clearance and effect of ${ }^{131} \mathrm{I}$-iodoinsulin in the peripheral tissues of normal, acromegalic and diabetic subjects. Clin. Sci. (Oxf.). 24: 331-341.

26. Bliss, C. I. 1976. Statistics in Biology. McGraw-Hill Book Company, New York. Vol. I. 215-218.

27. Maxwell, M. H., and C. R. Kleeman. 1962. Clinical disorders of fluid and electrolyte metabolism. McGraw-Hill Book Company, New York. 14-20.

28. Cox, R. W., and R. H. Williams. 1957. Studies on the action of oral hypoglycemic compounds. Metab. Clin. Exp. 5: 801-806.

29. Mirsky, I. A., G. Perisutti, and D. Diengatt. 1956. The inhibition of insulinase by hypoglycemic sulfonamides. Metab. Clin. Exp. 5: 156-161.

30. Feldman, J. M., and H. E. Lebovitz. 1969. Appraisal of the extrapancreatic actions of sulfonylureas. Arch. Intern. Med. 123: 314-322.

31. Ooms, H. A., Y. Arnold, U. Rosa, G. F. Pennisi, and J. R. M. Franckson. 1968. Total metabolic clearance of crystalline insulin and radioiodine-substituted insulin. Pathol. Biol. 16: 241-248.

32. Arquilla, E. R., H. Ooms, and K. Mercola. 1968. Immunological and biological properties of iodoinsulin labeled with one or less atoms of iodine per molecule. J. Clin. Invest. 47: 474-483.

33. Silvers, A., R. S. Swenson, J. W. Farquhar, and G. M. Reaven. 1969. Derivation of a three compartment model describing disappearance of plasma insulin- $I^{131}$ in man. J. Clin. Invest. 48: 1461-1469.

34. Franckson, J. R. M., R. Vanroux, R. Leclercq, $H$.
Brunengraber, and H. A. Ooms. 1971. Labelled insulin catabolism and pancreatic responsiveness during longterm exercise in man. Horm. Metab. Res. 3: 366-373.

35. Sönksen, P. H., C. V. Tompkins, M. C. Srivastava, and J. D. N. Nabarro. 1973. A comparative study on the metabolism of human insulin and porcine proinsulin in man. Clin. Sci. (Oxf.). 45: 633-654.

36. Izzo, J. L., J. W. Bartlett, A. Roncone, M. J. Izzo, and W. F. Bale. 1967. Physiological process and dynamics in the disposition of small and large dose of biologically active and inactive ${ }^{131} \mathrm{I}$-insulins in the rat. J. Biol. Chem. 242: 2343-2355.

37. Izzo, J. L., A. Roncone, M. J. Izzo, R. Foley, and J. W. Bartlett. 1972. Degradation of ${ }^{131} \mathrm{I}$-insulins by rat liver. J. Biol. Chem. 247: 1219-1226.

38. Schneider, B., E. Straus, and R. S. Yalow. 1976. Some considerations in the preparation of radioiodoinsulin for radioimmunoassay and receptor assay. Diabetes. 25: 260-267.

39. Gliemann, J., S. Gammeltoft, and J. Vinten. 1975. Timecourse of insulin-receptor binding and insulin-induced lipogenesis in isolated rat fat cells. J. Biol. Chem. 250: 3368-3374.

40. Le Cam, A., P. Freychet, and P. Lenoir. 1975. Degradation of insulin by isolated rat liver cells. Diabetes. 24: $566-573$.

41. Antoniades, H. N. 1976. Metabolism of single-component and high-molecular-weight radioactive insulin in rats. Endocrinology. 99: 481-487.

42. Roy, C. C., D. J. Shapcott, and D. O'Brien. 1968. The case for an 'abnormal' insulin in diabetes mellitus. Diabetologia. 4: 111-117.

43. Yalow, R. 1976. Methods in Radioimmunoassay of Peptide Hormones. North-Holland Publishing Company, Amsterdam. 1-23.

44. Reaven, G. M., R. Bernstein, B. Davies, and J. M Olefsky. 1976. Nonketotic diabetes mellitus: insulin deficiency or insulin resistance? Am. J. Med. 60: 80-88.

45. Parving, H. H., and S. Munkgaard Rasmussen. 1973. Transcapillary escape rate of albumin and plasma volume in short- and long-term juvenile diabetics. Scand. J. Clin. Lab. Invest. 32: 81-87.

46. Parving, H. H. 1976. Increased microvascular permeability to plasma proteins in short- and long-term juvenile diabetics. Diabetes. 25(Suppl. 2): 884-889.

47. Gundersen, H. J. G., and N. J. Christensen. 1977. Intravenous insulin causing loss of intravascular water and albumin and increased adrenergic nervous activity in diabetics. Diabetes. 26: 551-557.

48. Rasio, E. A., C. L. Hampers, J. S. Soeldner, and G. F. Cahill, Jr. 1967. Diffusion of glucose, insulin, inulin, and Evans blue protein into thoracic duct lymph of man. J. Clin. Invest. 46: 903-910.

49. Christlieb, A. R. 1974. Renin, angiotensin, and norepinephrine in alloxan diabetes. Diabetes. 23: 962-970.

50. Katz, M. A. 1973. Hyperglycemia-induced hyponatremia: calculation of expected serum sodium depression. $N$. Engl. J. Med. 289: 843-844.

51. Renkin, E. M. 1968. Capillary permeability. In Lymph and the Lymphatic System. H. S. Mayerson, editor. Charles C. Thomas Publisher, Springfield, Ill. 76.

52. Stern, M. P., J. W. Farquhar, A. Sivers, and G. M. Reaven. 1968. Insulin delivery rate into plasma in normal and diabetic subjects. J. Clin. Invest. 47: 19471957.

53. Turner, R. C., J. A. Grayburn, G. M. Newman, and J. D. N. Nabarro. 1971. Measurement of the insulin delivery rate in man. J. Clin. Endocrinol. Metab. 33: 279-286. 